\title{
Accelerated partial breast irradiation: multi-catheter interstitial brachytherapy
}

\author{
L. W. Cuttino, J. R. Kelley, D. W. Arthur \\ Department of Radiation Oncology, Virginia Commonwealth University Health System, \\ Richmond, VA, USA.
}

\begin{abstract}
Historically, adjuvant radiotherapy for early-stage breast cancer has included treatment of the entire breast. Breast conservation therapy (BCT), which employs whole-breast radiotherapy following lumpectomy, requires daily treatment for 5-7 weeks. The length of this treatment course proves difficult for some patients. In response, accelerated partial breast irradiation (APBI) has been investigated as a possible alternative to conventional post-lumpectomy treatment. This approach not only challenges the conventional treatment paradigm of whole-breast radiotherapy by reducing the treated volume, but also intensifies the dose delivered. By limiting the volume of breast tissue treated, the radiation dose delivery can be safely accelerated and the treatment time reduced to 5 days. In the United States, APBI has been most commonly delivered via brachytherapy (by either a multi-catheter implant or Mammosite balloon device) or by three-dimensional conformal radiotherapy (3D-CRT). One of the first techniques developed for APBI was multi-catheter interstitial brachytherapy. This article reviews completed trials of ABPI using the multi-catheter approach, as well as patient selection, placement technique, and dosimetric evaluation.
\end{abstract}

Keywords: Accelerated partial breast irradiation; Brachytherapy; Breast cancer; Radiotherapy

\section{Rationale}

The accepted approach to breast conservation therapy (BCT) for early-stage breast cancer is the surgical removal of the primary breast lesion followed by whole-breast radiotherapy. With this approach, inbreast control rates exceeding $90 \%$ can be expected [1-4]. Standard of care presently dictates that all women should receive radiation after breast conservation surgery to optimize local control rates regardless of age or tumor size, however, the protracted course of whole-breast radiotherapy can present a logistical problem for many patients.

Correspondence to: D. W. Arthur, MD, Department of Radiation Oncology, Virginia Commonwealth University, 401 College Street, Box 980058, Richmond, VA 23298, USA. E-mail: darthur@mcvh-vcu.edu; Tel: +1 804 828 7232; Fax: +1 8048287981

Publication date 31/05/05

BCO/364/2005/FO
Review of both clinical and pathologic evidence finds that there are scarce data to support the concept that the entire breast requires treatment. In fact, review of pathologic and clinical failure patterns suggest that the primary target requiring treatment is likely limited to a $1-2 \mathrm{~cm}$ margin around the edge of the lumpectomy cavity [5-14]. If indeed the target volume can be restricted to a portion of the breast, then this reduction in volume provides the opportunity to accelerate the dose delivery while avoiding an increase in normal tissue toxicity.

\section{Patient selection}

Patients with a significant risk of harboring microscopic disease within the breast, but located outside of the stated treatment target $(1-2 \mathrm{~cm}$ beyond the lumpectomy cavity), are not optimal candidates for accelerated partial breast irradiation (APBI). Two societies have endorsed conservative patient selection 
criteria and avoided the use of APBI in patients with a risk of disease remote from the lumpectomy cavity $[15,16]$. The American Brachytherapy Society patient selection criteria include: patients $\geqslant 45$ years of age, invasive ductal carcinoma only, tumor size of $\leqslant 3 \mathrm{~cm}$, negative resection margins (no tumor on ink), and a negative axillary nodal status. Similarly, the American Society of Breast Surgeons selection criteria include: patients $\geqslant 50$ years of age, invasive ductal carcinoma or ductal carcinoma-in-situ, tumor size of $\leqslant 2 \mathrm{~cm}$, negative resection margins (defined as at least $2 \mathrm{~mm}$ in all directions), and a negative axillary nodal status. An extensive intra-ductal component, limited positive-nodal status, infiltrating lobular histology, ductal carcinoma-in-situ, and young age have been used as exclusion criteria based on the successful early APBI treatment experiences.

\section{Treatment technique}

The multi-catheter interstitial brachytherapy approach is the APBI technique that has been in use the longest and has the most extensive follow-up [17]. With this approach, after-loading catheters are placed through the breast tissue surrounding the lumpectomy cavity. In general, catheters are placed in two to three planes, with an inter-catheter spacing of $1.0-1.5 \mathrm{~cm}$, and an inter-planar separation not exceeding $3 \mathrm{~cm}$. These implants generally require $14-20$ catheters to assure proper dose coverage. The exact number of planes and catheters is determined by the size and shape of the target using established brachytherapy dosimetric guidelines $[18,19]$. Dosimetric treatment planning is then completed.

To assure that the goals of target coverage and dose homogeneity are achieved, advances in placement technique have been necessary to reduce the degree of operator dependence and improve the reproducibility of the procedure. The incorporation of image-guidance and computed tomography (CT)based 3D planning has made a significant impact on the quality of multi-catheter brachytherapy implants. Several approaches have been established that allow physicians to adjust a technique to their specific clinical practice. Kuske [20] has described a method of closed-cavity implantation that is performed under local anesthesia. A biologically compatible contrast material is injected into the lumpectomy cavity under ultrasound guidance, revealing its shape and extent. A template system is used to place catheters under real-time fluoroscopic or mammographic guidance. Accurate coverage of the cavity is verified before the completion of the procedure.

At Virginia Commonwealth University, catheters are placed under real-time CT guidance [21]. The procedure is performed in the radiation oncology
CT-simulation suite, under local anesthesia with conscious sedation. Initial guide catheters are placed based on the appearance of the cavity on a prebrachytherapy CT scan. An intra-operative CT scan is then obtained to evaluate the position of the guide catheters in relation to the lumpectomy cavity, and adjustments are made as necessary. Catheters are placed free-hand, although a template could be incorporated with this approach. The implant is completed, and a final CT scan is obtained and transferred to the 3D planning system. The entire procedure, from the initial catheter placement to image acquisition for treatment planning, is completed in 1.5-2 $\mathrm{h}$.

Another important development is the creation of conceptual tools to allow the quality of the implant to be assessed for both target coverage and dose homogeneity so that treatment experiences can be compared, local control optimized, and toxicity avoided. The incorporation of CT-based 3D planning has replaced two-dimensional (2D) planning as the standard of care. These planning systems allow for the calculation of dose-volume parameters (such as the volume of breast tissue receiving $100 \%, 150 \%$, and $200 \%$ of the prescription dose) which appear to correlate with the incidence of fat necrosis, skin toxicity, and the development of fibrosis $[4,22,23]$.

With the incorporation of image-guided catheter placement techniques (stereotactic mammography, ultrasound or CT-guided) and 3D dosimetric planning, the multi-catheter approach has evolved into a reliable and reproducible technique. This approach is the most adaptable APBI technique and can be used in a variety of treatment situations, regardless of lumpectomy cavity size, shape, or location within the breast.

\section{Treatment experience}

The number of published ABPI experiences continues to increase yearly. The majority of the patients treated with the longest follow-up in these reports have been treated with the multi-catheter interstitial technique. The successful published interstitial brachytherapy experiences are summarized in Table 1 [22,24-34]. Collectively, these trials represent an experience of hundreds of patients and demonstrate in-breast failure rates of less than $5 \%$. These treatment experiences share in common conservative selection criteria and treatment delivery techniques that assured the coverage of an appropriately defined target. In three reports [35-37], unacceptable in-breast disease control rates were observed (Table 2). These higher rates of inbreast failure appear to be directly related to the lack of patient selection criteria and/or treatment quality assurance. For example, microscopic margin assessment was not employed in the earlier Guy's Hospital 
Table 1. Successful multi-catheter APBI series.

\begin{tabular}{|c|c|c|c|c|}
\hline Institution & Number of cases & $\begin{array}{l}\text { Median follow-up } \\
\text { (months) }\end{array}$ & $\begin{array}{l}5 \text {-year actuarial } \\
\text { recurrence rate total (\%) }\end{array}$ & $\begin{array}{l}5 \text {-year elsewhere } \\
\text { failure rate }(\%)\end{array}$ \\
\hline \multicolumn{5}{|l|}{ William Beaumont Hospital [24] } \\
\hline Total & 199 & 65 & 1 & 0.6 \\
\hline Low-dose-rate protocol & 120 & 82 & 0.9 & 0 \\
\hline High-dose-rate protocol & 79 & 52 & 2.1 & 2.1 \\
\hline Ochsner Clinic [25] & 160 & 84 & $2.5^{\star}$ & $1.2^{*}$ \\
\hline Virginia Commonwealth University [26] & 44 & 42 & 0 & 0 \\
\hline RTOG 95-17 [27] & 99 & 44 & 3 & - \\
\hline University of Kansas [28] & 25 & 47 & 0 & - \\
\hline University of Pisa, Italy [29] & 90 & 27 & 4.4 & - \\
\hline Massachusetts General Hospital [30] & 48 & 23 & 0 & - \\
\hline Tufts/Brown Universities [22] & 33 & 58 & $6^{*}$ & $6^{*}$ \\
\hline University of Wisconsin [31] & 50 & - & - & - \\
\hline \multicolumn{5}{|l|}{ National Institute of Oncology, } \\
\hline Hungary phase I/II trial $[32,33]$ & 45 & 80 & $6.7^{*}$ & $6.7^{\star}$ \\
\hline \multicolumn{5}{|l|}{ National Institute of Oncology, } \\
\hline Hungary phase III trial $[32,34]$ & 119 & 30 & $2.5^{\star}$ & $1.7^{\star}$ \\
\hline
\end{tabular}

RTOG: Radiation Therapy Oncology Group.

${ }^{*}$ Crude rate.

Table 2. Multi-catheter APBI series with unfavorable results.

\begin{tabular}{llllr}
\hline Institution & Number of cases & $\begin{array}{l}\text { Median follow-up } \\
\text { (months) }\end{array}$ & $\begin{array}{l}\text { 5-year actuarial } \\
\text { recurrence rate total (\%) }\end{array}$ & $\begin{array}{l}\text { 5-year elsewhere } \\
\text { failure rate (\%) }\end{array}$ \\
\hline Guy's Hospital [35] & 27 & 72 & 37 & - \\
Guy's Hospital II [36] & 50 & 60 & 18 & 4 \\
London Regional Cancer Center [37] & 39 & 91 & 16.2 & 10 \\
\hline
\end{tabular}

experience and it is not clear whether the patients treated were appropriate for breast conservation at all. Additionally, the authors themselves question the methods of target delineation and the ability to confirm dosimetric coverage of the target [35]. At the London Regional Cancer Center, the target appears to have been limited to the cavity only, without surrounding tissue at risk included, questioning the validity of their target delineation and coverage [37]. These publications further validate that the success of APBI is dependent on proper patient selection and quality assurance of treatment delivery.

\section{Future directions}

With the emergence of simplified brachytherapy techniques (balloon catheter) and non-invasive approaches (3D-CRT), the use of multi-catheter brachytherapy is likely to be limited to specific centers in selected patients. Continued studies are necessary to address questions regarding patient selection criteria and details of treatment technique. With the continued reporting of the initial trials and the initiation of additional single and multi-institutional phase I/II trials and phase III prospective randomized trials, these questions will be appropriately addressed and further define the role of APBI in the management of early-stage breast cancer.

\section{References}

1. Fisher B, Anderson S, Bryant J, et al. Twenty-year followup of a randomized trial comparing total mastectomy, lumpectomy, and lumpectomy plus irradiation for the treatment of invasive breast cancer. New Engl $\mathrm{J}$ Med 2002; 347: 1233-1241.

2. Veronesi U, Cascinelli N, Mariani L, et al. Twenty-year follow-up of randomized study comparing breastconserving surgery with radical (Halstead) mastectomy for early breast cancer. New Engl J Med 2002; 347: 1227-1232.

3. Vrieling $\mathrm{C}$, Collete L, Fourquet $\mathrm{A}$, et al. The influence of the boost in breast-conserving therapy on cosmetic outcome in the IORTC 'boost versus no boost' trial. Int $J$ Radiat Oncol Biol Phys 1999; 45: 677-685.

4. Wazer D, Dipertillo T, Schmidt-Ullrich R, et al. Factors influencing cosmetic outcome and complication risk after conservative surgery and radiotherapy for early-stage breast carcinoma. J Clin Oncol 1992; 10: 356-363. 
5. Faverly D, Holland R, Burgers L. An original stereomicroscopic analysis of the mammary glandular tree. Virchows Arch A Pathol Anat Histopathol 1992; 421: 115-119.

6. Faverly $\mathrm{D}$, Burgers $\mathrm{L}$, Bult $\mathrm{P}$, et al. Three dimensional imaging of mammary ductal carcinoma in situ: clinical implications. Semin Diagn Pathol 1994; 11: 193-198.

7. Imamura H, Haga S, Shimizu $\mathrm{T}$, et al. Relationship between the morphological and biological characteristics of intraductal components accompanying invasive ductal breast carcinoma and patient age. Breast Cancer Res Treat 2000; 62: 177-184.

8. Ohtake T, Abe R, Kimijima I, et al. Intraductal extension of primary invasive breast carcinoma treated by breastconservative surgery. Cancer 1995; 76: 32-45.

9. Clark R, Wilkinson R, Miceli P, et al. Breast cancer: experiences with conservation therapy. Am J Clin Oncol 1987; 10: 461-468.

10. Veronesi U, Marubini E, Mariani L, et al. Radiotherapy after breast-conserving surgery in small breast carcinoma: long-term results of a randomized trial. Ann Oncol 2001; 12: 997-1003.

11. Clark R, McCulloch P, Levine M, et al. Randomized clinical trial to assess the effectiveness of breast irradiation following lumpectomy and axillary dissection for nodenegative breast cancer. J Natl Cancer Inst 1992; 84: 683-689.

12. Uppsala-Oreboro Breast Cancer Study Group. Sector resection with or without post-operative radiotherapy for stage I breast cancer: a randomized trial. J Natl Cancer Inst 1990; 82: 277-282.

13. Fisher B, Anderson S. Conservative surgery for the management of invasive and non-invasive carcinoma of the breast: NSABP trials. World J Surg 1994; 18: 63-69.

14. Holli K, Saaristo R, Isola J, et al. Lumpectomy with or without postoperative radiotherapy for breast cancer with favourable prognostic features: results of a randomised study. Br J Cancer 2001; 84: 164-169.

15. Arthur D, Vicini F, Kuske $R$, et al. Accelerated partial breast irradiation: an updated report from the American Brachytherapy Society. Brachytherapy 2003; 2: 124-130.

16. American Society of Breast Surgeons. Consensus statement for accelerated partial breast irradiation. http:// www.breastsurgeons.org/officialstmts/officialstmt3.html (last accessed April 30, 2003).

17. Arthur D, Vicini F. Accelerated partial breast irradiation as part of breast conservation therapy. J Clin Oncol 2005; 23: 1726-1735.

18. Zwicker R, Arthur D, Kavanagh B, et al. Optimization of planar high-dose-rate implants. Int $J$ Radiat Biol Phys 1999; 44: 1171-1177.

19. Zwicker R, Schmidt-Ullrich R. Dose uniformity in a planar implant system. Int J Radiat Biol Phys 1995; 31: 149-155.

20. Kuske R. Breast brachytherapy. Hematol Oncol Clin North Am 1999; 13: 543-558.

21. Cuttino L, Arthur D, Todor D, et al. CT-guided multicatheter insertion technique for partial breast brachytherapy (PBB): reliable target coverage and dose homogeneity. Brachytherapy 2005; 4: 10-17.

22. Wazer D, Berle L, Graham R, et al. Preliminary results of a phase I/II study of HDR brachytherapy alone for T1/T2 breast cancer. Int J Radiat Oncol Biol Phys 2002; 53: 889-897.
23. Arthur D, Wazer D, Koo D, et al. The importance of dosevolume histogram evaluation in partial breast brachytherapy: a study of dosimetric parameters [Abstract]. Int $J$ Radiat Oncol Biol Phys 2003; 57: S361-S362.

24. Vicini F, Kestin L, Chen $P$, et al. Limited-field radiation therapy in the management of early-stage breast cancer. J Natl Cancer Inst 2003; 95: 1205-1210.

25. King T, Bolton J, Kuske R, et al. Long-term results of wide-field brachytherapy as the sole method of radiation therapy after segmental mastectomy for $\mathrm{T}$ (is, 1, 2) breast cancer. Am J Surg 2000; 180: 299-304.

26. Arthur D, Koo D, Zwicker R. Partial breast brachytherapy following lumpectomy: a low dose rate and high dose rate experience. Int $J$ Radiat Oncol Biol Phys 2003; 56: 681-689.

27. Kuske R, Winter $\mathrm{K}$, Arthur D, et al. A phase II trial of brachytherapy alone following lumpectomy for stage I or II breast cancer: initial outcomes of RTOG 95-17 [Abstract 565]. Proc Am Soc Clin Oncol 2004; 23: 18.

28. Krishnan L, Jewell W, Tawfik O, et al. Breast conservation therapy with tumor bed irradiation alone in a selected group of patients with stage I breast cancer. Breast $J$ 2001; 7: 91-96.

29. Cionini L, Pacini P, Marzano S. Exclusive brachytherapy after conservative surgery in cancer of the breast. Lyon Chir 1993; 89: 128.

30. Lawenda B, Taghian A, Kachnic L, et al. Dose-volume analysis of radiotherapy for T1N0 invasive breast cancer treated by local excision and partial breast irradiation by low-dose-rate interstitial implant. Int J Radiat Oncol Biol Phys 2003; 56: 671-680.

31. Das R, Patel R, Shah H, et al. 3D CT-based high-dose rate breast brachytherapy implants: treatment planning and quality assurance. Int J Radiat Oncol Biol Phys 2004; 59: 1224-1228.

32. Polgar C, Sulyok Z, Fodor J, et al. Sole brachytherapy of the tumor bed after conservative surgery for $\mathrm{T} 1$ breast cancer: five-year results of a phase I/II study and initial findings of a randomized phase III trial. J Surg Oncol 2002; 80: 121-128.

33. Polgar C, Major T, Fodor J, et al. High-dose rate bracytherapy alone versus whole breast radiotherapy with or without tumor bed boost after breast conserving surgery: seven year results of a comparative study. Int $J$ Radiat Oncol Biol Phys 2004; 60: 1171-1181.

34. Vicini F, Arthur D, Polgar C, et al. Defining the efficacy of accelerated partial breast irradiation: the importance of proper patient selection, quality assurance, and common sense. Int J Radiat Oncol Biol Phys 2003; 57: 1210-1213.

35. Fentiman I, Poole C, Tong D, et al. Inadequacy of iridium implant as sole radiation treatment for operable breast cancer. Eur J Cancer 1996; 32A: 608-611.

36. Fentiman I, Deshmane V, Tong D, et al. Caesium (137) implant as sole radiation therapy for operable breast cancer: a phase II trial. Radiother Oncol 2004; 71: 281-285.

37. Perera F, Yu E, Engel J, et al. Patterns of breast recurrence in a pilot study of brachytherapy confined to the lumpectomy site for early breast cancer with six years' minimum follow-up. Int J Radiat Oncol Biol Phys 2003; 57: $1239-1246$. 